\title{
AN ANN BASED PI CONTROLLER FOR A SUPERCONDUCTING GENERATOR
}

\author{
G. A. Morsy \\ T. A. Mohammed \\ Dept. of Elect. Eng., Faculty of Eng., Menoufya Univ., Egypt
}

\section{ABSTRACT}

The paper presents a coordinated artificial neural network (ANN) based proportional plus-integral (PI) controller for a superconducting generator (SCG). The ANN controller was trained using data groups, that covers the whole P-Q plane. These data groups obtained from a PI controller implemented on the governor control loop. To test the present control strategy, a fairly detailed nonlinear model of the SCG is used to assure accuracy and validity of the proposed control structure. The simulation results are presented in comparison with similar results which obtained using the conventional PI controller. The simulation results reveal that the ANN control design approach can be implemented to design controllers for the SCG and give results similar to those of conventional controllers.

\section{1-INTRODUCTION}

The natural growth of population renders continuous increase in electric power demand. One way of overcoming this problem is to develop SCGs. This machine offers a lot of advantages over the conventional synchronous machines and has the capability to supply greater base load with higher efficiency $[1,2]$. However, SCGs have a complex structure and require materials different from those normally used in conventional generators. This is due to that the high current density of the superconducting field winding obviates the need for any magnetic circuit in the SCG. For this reason all armature windings contemplated for SCG are of the air cored winding type. Also, the rotor incorporates in addition to the super- conducting field winding, a helium management system and two eddy-current screens $[3,4]$. The outer screen acts as a damper has time constant suitable for the damping purpose and the inner screen acts as an electromagnetic shield has a time constant sufficiently long to shield the field winding from time changing magnetic fields [5].

Manuscript received from $\mathrm{Dr}$.G.A. Morsy

Accepted on : $17 / 6 / 2001$

Engineering Research Journal Vol 24,No 3, 2001 Minufiya University, Faculty of

Engineering, Shebien El-Kom, Egypt , ISSN 1110-1180 
From the control stand point, the SCG requires special attention and considerations. This is due to that SCG has almost a zero resistance field winding and consequently an extremely long of the field circuit time constant, it has been indicated that excitation control becomes ineffective $[6,7]$. So, it is necessary to consider only the governor control loop to enhance the system performance. Various types of controllers such as phase-advance and proportional plus-integral have been employed. The parameters of these controllers are normally fixed at certain values which are determined for a particular operating conditions. In daily operation of power system the operating conditions changes as a result of load changes or other disturbances. Thus, a set of controller parameters which insure good performance under a certain operating conditions may no longer yield satisfactory results for others. To overcome this problems, self tuning controllers were adapted and developed to maintain better performance under a wide range of operating conditions [8]. This controller was designed and implemented on the governor loop of the SCG and successful simulation results were obtained. However, the self tuning controllers suffers from the necessity of obtaining a suitable identification algorithm to estimate the model parameters every sampling interval and this may face practical problems.

In recent years, an ANNs have attracted considerable attention as candidates for novel computational systems because of the variety of advantages that they offer over the conventional computational systems. Among those advantages, the ability to memorize, rapidity and robustness are the most profound and interesting properties which have attracted attention in many fields. Since 1989, ANN methodology has captured the interest in electrical power engineering and it is promise, if it is properly trained, to ensure effective damping action in the face of large disturbances. This is due to the adaptive nature of the ANN and thus it will overcome the problem of tuning the parameters as the power system configuration change. Many published papers were developed ANN schemes for the conventional synchronous generators which trained using power system stabilizer [9-11].

As a step forward in the power system control area, this paper introduces the ANN control strategy as an alternative approach to improve the low inherent damping characteristics of the SCGs. The ANN scheme was trained using data groups obtained from the conventional PI control on the governor loop at the SCG. The proposed structure of the ANN controller has an input layer, an output layer and one hidden layer. The simulation results obtained using a detailed nonlinear model and pressed in comparison with those obtained with conventional PI controller emphasizing robustness and flexibility of the proposed ANN controller.

\section{POWER SYSTEM MODEL}

The power system model used in this study is shown in Fig.(1). It consists of a SCG connected to an infinite bus via a double circuit transmission line and a transformer. The generator is driven by a three-stage steam turbine with reheat and fast acting electro-hydraulic governor. A selection switch has been used to consider the control action. 


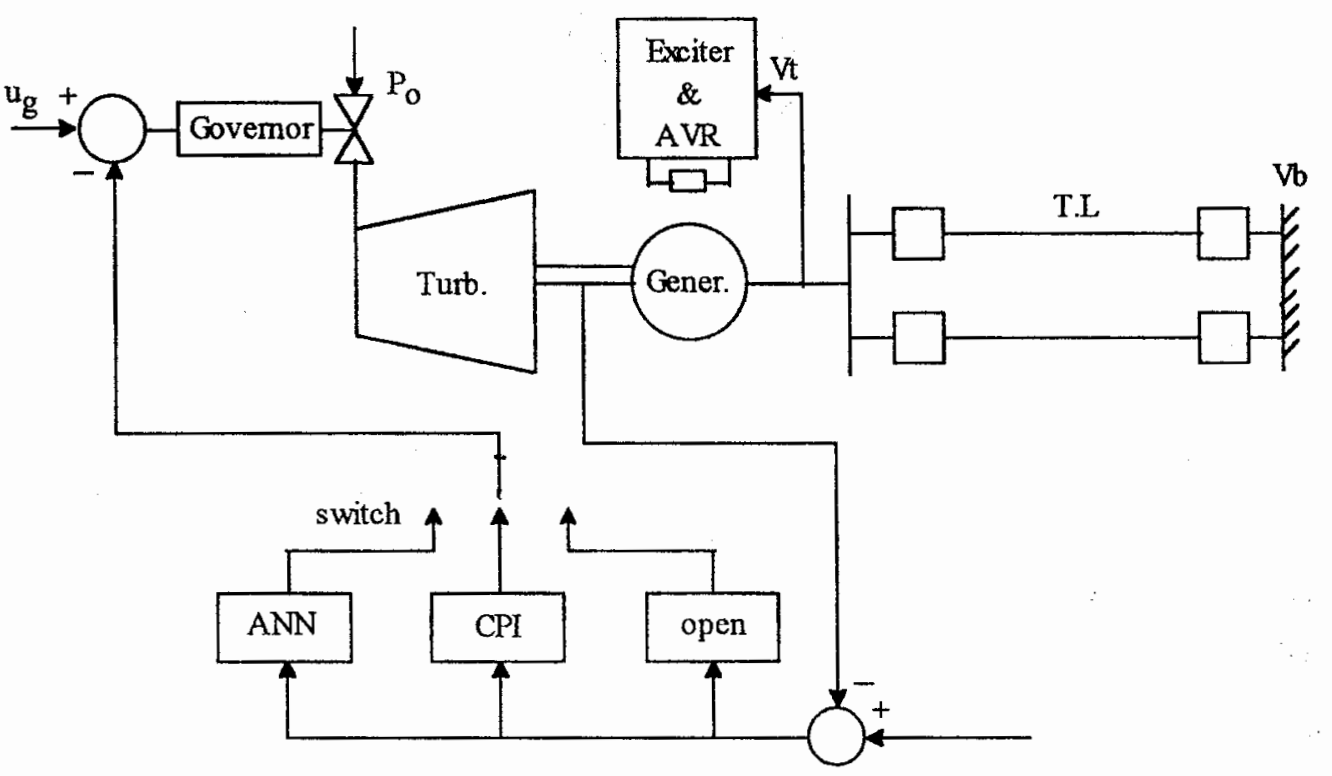

Fig. (1) Power system under consideration

The state equations represented the SCG may be written as [8]:

$$
\begin{aligned}
& p \psi_{f}=\omega_{o}\left(V_{f}-i_{f} R_{f}\right) \\
& p \psi_{d}=\omega_{o}\left(V_{d}+i_{d}\left(R_{a}+R_{e}\right)+\psi_{q}\right)+\omega \psi_{q} \\
& p \psi_{q}=\omega_{o}\left(V_{q}+i_{q}\left(R_{a}+R_{e}\right)-\psi_{d}\right)-\omega \psi_{d} \\
& p \psi_{D 1}=-\omega_{o} i_{D 1} R_{D 1} \\
& p \psi_{Q 1}=-\omega_{o} i_{Q 1} R_{Q 1} \\
& p \psi_{D 2}=-\omega_{o} i_{D 2} R_{D 2} \\
& p \psi_{Q 2}=-\omega_{o} i_{Q 2} R_{Q 2} \\
& p \delta=\omega \\
& \mathrm{p} \omega=\frac{\omega_{o}}{2 \mathrm{H}}\left(\mathrm{T}_{\mathrm{m}}-\mathrm{T}_{\mathrm{e}}\right) \\
& T_{e}=\psi_{d} i_{q}-\psi_{q} i_{d}
\end{aligned}
$$

Where :-

$$
\left[\begin{array}{c}
\Psi_{d} \\
\Psi_{D 1} \\
\Psi_{D 2} \\
\Psi_{f}
\end{array}\right]=\left[\begin{array}{cccc}
-\left(X_{d}+X_{e}\right) & X_{d D 1} & X_{d D 2} & X_{d f} \\
-X_{d D 1} & X_{D 1} & X_{D 1 D 2} & X_{\mathrm{fD} 1} \\
-X_{d D 2} & X_{D 1 D 2} & X_{D 2} & X_{f D 2} \\
-X_{d f} & X_{f D 1} & X_{f D 2} & X_{f}
\end{array}\right]\left[\begin{array}{c}
i_{d} \\
i_{D 1} \\
i_{D 2} \\
i_{f}
\end{array}\right]
$$


$\left[\begin{array}{c}\Psi_{\mathrm{q}} \\ \Psi_{\mathrm{Q} 1} \\ \Psi_{\mathrm{Q} 2}\end{array}\right]=\left[\begin{array}{ccc}-\left(\mathrm{X}_{\mathrm{q}}+\mathrm{X}_{\mathrm{e}}\right) & \mathrm{X}_{\mathrm{qQ1}} & \mathrm{X}_{\mathrm{qQ2}} \\ -\mathrm{X}_{\mathrm{qQ1}} & \mathrm{X}_{\mathrm{Q} 1} & \mathrm{X}_{\mathrm{Q} 1 \mathrm{Q} 2} \\ -\mathrm{X}_{\mathrm{qQ2}} & \mathrm{X}_{\mathrm{Q} 1 \mathrm{Q} 2} & \mathrm{X}_{\mathrm{Q} 2}\end{array}\right]=\left[\begin{array}{c}\mathrm{i}_{\mathrm{q}} \\ \mathrm{i}_{\mathrm{Q} 1} \\ \mathrm{i}_{\mathrm{Q} 2}\end{array}\right]$

The transmission system is includeed in the model, replacing $R_{a}$ by $\left(R_{a}+R_{e}\right)$ and $X_{d}$ and $X_{q}$ by $\left(X_{d}+X_{e}\right)$ and $\left(X_{q}+X_{e}\right)$ respectively.

The model of the three-stage steam turbine with reheat and the electrohydraulic governor considered in this study follows the IEEE standared representation and the special IEEE recommendations for the turbine of the SCG. Their state equations may be written as:

$$
\begin{aligned}
& p Y_{H P}=\left(G_{M} P_{o}-Y_{H P}\right) / T_{H P} \\
& p Y_{R P}=\left(Y_{H P}-Y_{R H}\right) / T_{R H} \\
& p Y_{I P}=\left(G_{l} Y_{R H}-Y_{I P}\right) / T_{I P} \\
& p Y_{L P}=\left(G_{I P}-Y_{L P}\right) / T_{L P} \\
& T_{m}=F_{H P} Y_{H P}+F_{I P} Y_{I P}+F_{L P} Y_{L P}
\end{aligned}
$$

The electro-hydraulic governor equations are :

$$
\begin{aligned}
& p G_{M}=\left(U_{G M}-G_{M}\right) / T_{G M} \\
& p G_{I}=\left(U_{G I}-G_{I}\right) / T_{G I}
\end{aligned}
$$

Where the position and rate limits are,

$0 \leq G_{M}, G_{1} \leq 1.0$ and $-6.7 \leq p G_{M}, p G_{1} \leq 6.7 \mathrm{p} . \mathrm{u} / \mathrm{sec}$

The system parameters are given in the Appendix.

\section{ANN METHODOLOGY}

The simple three layers structure, very popular model of ANN is shown in Fig.(2). The input vector to the network may be defined as :[ $\Delta \omega(t), \Delta \omega(t-1)$, $\Delta \omega(\mathrm{t}-2), \Delta \omega(\mathrm{t}-3)]$. The output of the ANN is the supplementary control signal.

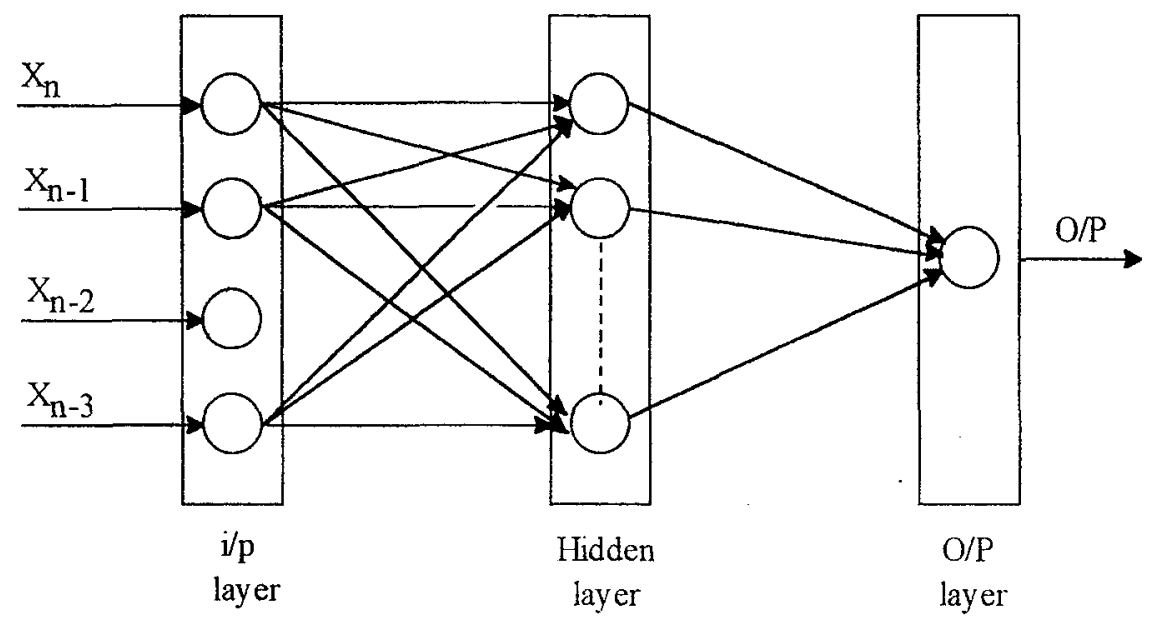

Fig. (2) ANN construction 
The neural network with error back propagation algorithm using delta rule, was trained with variety of input-output pattern sets of data groups obtained by the conventional PI controller. Then, the weights and biases for each loop were calculated [12].

Derivation of back propagation algorithm:

1- Set the normalized input and target output data (for training and testing)

2- Set the network structure [no. of samples trained, no. of hidden layers and no. of units in each hidden layer, learning rates, stop error criteria (E) ].

3- Initialize interconnection weights ( set all weights and node thresholds to small random numbers)

4- Calculate the actual output for each test pattern.

5- Calculate the mean square error for each output and for each pattern :

$$
\mathrm{e}_{\mathrm{I}}=\frac{1}{2} \sum_{\mathrm{i}=0}^{\text {patterns }} \sum_{\mathrm{j}=0}^{\text {outputs }}(\text { desired } \mathrm{o} / \mathrm{p}-\text { actual } \mathrm{o} / \mathrm{p})^{2}
$$

6- If $\mathrm{e}_{\mathrm{I}}>\mathrm{E}$, tune the interconnection weights by error gradient method:

$$
\mathrm{W}_{\mathrm{ji}}(\mathrm{t}+1)=\mathrm{W}_{\mathrm{ji}}(\mathrm{t})+\Delta \mathrm{W}_{\mathrm{ji}}
$$

Where: $W_{j i}(t)$ is weight from unit $i$ to unit $j$ at time $t$.

and $\Delta w_{\mathrm{ji}}$ is the weight adjustment $=\eta \delta_{\mathrm{j}} \theta_{\mathrm{i}}$

$\eta$ : Learning rate $\quad 0<\eta<1$

$\delta_{j}:$ the error gradient at unit $j$

* for output units:

$$
\delta_{\mathrm{j}}=\theta_{\mathrm{j}}\left(1-\theta_{\mathrm{j}}\right)(\text { desired } \mathrm{o} / \mathrm{p}-\text { actual o/p })_{j}
$$

* for the hidden units:

$$
\delta_{\mathrm{j}}=\theta_{\mathrm{j}}\left(1-\theta_{\mathrm{j}}\right) \sum \delta_{\mathrm{k}} \mathrm{W}_{\mathrm{kj}}
$$

$\delta_{k}$ : the error gradient at unit $k$ which a connection point from hidden unit $j$.

7- Repeat iterations until convergence in terms of the selected error criteria.

When the stop conditions are met and the network reaches its designed goal, then save the network structure and the interconnections weights.

After training, the ANN can be used to estimate the input-output mapping even from inexact input information. Therefore, the ANN network was introduced to replace the conventional PI controller and acts as an intelligent digital controller through the governor loop of the SCG.

\section{SIMULATION RESULTS}

The designed ANN were implemented in the governing loop of the SCG and the system performance were examined at different operating conditions to different disturbances. The system nonlinear simulation results for a symmetrical three-phase short circuit which is the most sever type of faults, of $120 \mathrm{~ms}$ duration, at the transformer high voltage side are shown in figures (3) - (5), for lead, lag and unity power factors respectively. These results illustrates that the system response with the proposed controller is just as good as that with the 
conventional PI controller, but with a slight increase in damping. Another type of disturbance is applied to the system, were the governor actuating input is raised suddenly to $10 \%$ over its nominal value for $100 \mathrm{~ms}$. The response of the system to this disturbance is shown in Fig.(6). It is shown that the system response with proposed controller closely follows that obtained by implementing the conventional PI controller.

\section{CONCLUSION}

The paper presents an ANN controller as an alternative approach to improve the low inherent damping and performance of the SCG. The concept of conventional PI controller has successfully extended to an ANN. Data used for training the ANN were collected from a system equipped with conventional PI controller over a wide range of operating conditions. The simulation results, which obtained at a wide range of operating conditions, show a robust design of the ANN due to its adaptive nature. This ensures the control strategy effectiveness and capabilities even with different disturbances and different operating conditions.

\section{Appendix}

\section{- SCG parameters}

2000 MVA, $1700 \mathrm{MW}, 3000 \mathrm{rpm}$

$X_{d}=X_{q}=0.453$ p.u.,$X_{f}=0.541$ p.u.

$X_{\mathrm{KD} 1}=X_{\mathrm{KQ} 1}=0.2567$ p.u. $\quad X_{\mathrm{FKD} 2}=0.3398$ p.u.

$\mathrm{X}_{\mathrm{af}}=\mathrm{X}_{\mathrm{fKD} 1}=\mathrm{X}_{\mathrm{ad} 1}=\mathrm{X}_{\mathrm{ad} 2}=\mathrm{X}_{\mathrm{KD} 1 \mathrm{KD} 2}=0.237$ p.u.

$X_{\mathrm{aq1}}=\mathrm{X}_{\mathrm{aq} 2}=\mathrm{X}_{\mathrm{KQ1}} \mathrm{K}_{\mathrm{Q} 2}=0.237$ p.u.

$\mathrm{R}_{\mathrm{KD} 1}=\mathrm{R}_{\mathrm{KQ1}}=0.01008$ p.u.

$\mathrm{R}_{\mathrm{a}}=0.003 \quad, \quad \mathrm{R}_{\mathrm{KD} 2}=\mathrm{R}_{\mathrm{KQ} 2}=0.00134$,

$\mathrm{H}=3 \mathrm{KWS} / \mathrm{KVA}$

\section{Transmission System Parameters}

$$
\begin{array}{ll}
X_{T}=0.15 \text { p.u. } \quad & , \quad R_{T}=0.0003 \text { p.u. } \\
X_{L} \quad=0.05 \text { p.u. } \quad, \quad & R_{L}=0.005 \text { p.u. }
\end{array}
$$

\section{- Parameters of Governor and Turbine}
$\mathrm{T}_{\mathrm{HP}}=0.1 \mathrm{sec}$.
$\mathrm{F}_{\mathrm{HP}}=0.26$,
$\mathrm{T}_{\mathrm{IP}}=0.3 \mathrm{sec}$,
$F_{\text {I.P }}=0.3 \mathrm{sec} \quad, \quad F_{\text {L.P }}=0.32$
$\mathrm{T}_{\mathrm{RH}}=10 \mathrm{sec}$.
$\mathrm{T}_{\mathrm{GM}}=\mathrm{T}_{\mathrm{G} . \mathrm{I}}=0.1 \mathrm{sec} . \quad, \quad \mathrm{P}_{\mathrm{o}}=1.2$ p.u. 


\section{REFERENCES}

1- S.M. Osheba et al., "Comparison of transient performance of superconducting and conventional generators in a multi-machine system", IEE Proc. Vol. 135, Pt. C., No. 5, PP 289-295, Sept. 1988.

2- M.A.A.S. Alyan and Y.H. Rahim, "A Discreet state space controller for superconducting turbogenerators", IEEE Trans. On EC-3, No. 2, PP. 300-304, June 1988.

3- K.Yamagushi, et al., "Rotor design of a $1000 \mathrm{MW}$ superconducting generator", IEEE Trans. On EC, Vol. 4, No. 2, June 1989.

4- A. H. M. S. Ula, et al., "The effect of design parameters on the dynamic behavior of The superconducting alternators", IEEE Trans. on EC, Vol. 3, No. 1, March 1988.

5- M.A.A.S. Alyan and Y.H. Rahim, "The role of governor control in transient stability of superconducting turbogenerator", IEEE Trans. On EC-2, No. 1, PP. 83-98, March 1987.

6- G.A. Morsy, A. Kinawy and S.M. Osheba, "Frequency domain analysis of a superconducting generator", Elect. Power System Research 30, PP. 107-113, 1994.

7- G.A. Morsy, H.A. Khattab and A. Kinawy, "Design of a PI controller for a superconducting generator", Eng. Research Blue. Vol. 23, No. 1, Fac. Of Eng., Men. Univ., PP. 61-77, Jan 2000.

8- G.P. Chen, O.P. Malik, et al., "An Adaptive power system stabilizer based on the self-optimizing pole shifting control strategy", submitted to IEEE/PES winter meeting 1993.

9- Y.Y. Has and C.R. Chen, "Tuning of power system stabilizer using an artificial neural network", IEEE/PES, Winter Meeting, New York, PP. 3-7, Feb. 1991.

10- Zhng et al., "An artificial neural network based adaptive power system stabilizer", IEEE trans. On EC-8, No. 1, PP. 71-77, March 1993.

11- E.A. Mohamed, M. Zakaria and A.H. Amer, "Efficient power system stabilizer configuration based on linear optimal control and ANN", MEPCON'2000, Ain Shams Univ. Egypt, PP. 330-337, March 2000.

12- D. Sarmandal,"An artificial neural network based power system stabilizer", M. Sc. Thesis, Indian Institute of Technology, Kharagpur,INDIA, 1996. 


\section{Nomenclature}

\section{$\mathrm{H}$ Inertia constant ( $\mathrm{kWs} / \mathrm{kVA})$}

I Current (p.u.)

p Differential operator

R Resistance (p.u.)

$\mathrm{T}$ Torque

V Voltage (p.u.)

$\mathrm{X}$ Resistance (p.u.)

\section{Greek letters}

$\delta \quad$ Rotor angle

$\psi \quad$ Flux linkage (p.u.)

$\omega \quad$ Angular speed $(\mathrm{rad} / \mathrm{s})$

\section{Subscripts}

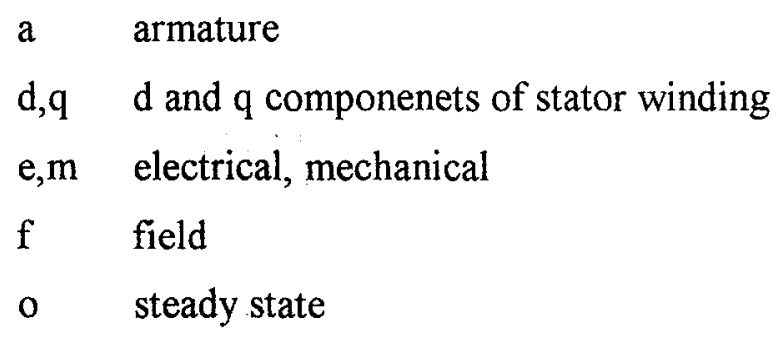

$\mathrm{FKD}_{1}, \mathrm{fKQ}_{1} \quad \mathrm{~d}$ and $\mathrm{q}$ mutual components between outer screen and field winding SCG

$\mathrm{FKD}_{2}, \mathrm{FKQ}_{2} \quad \mathrm{~d}$ and $\mathrm{q}$ mutual . components between inner screen and field winding SCG

$\mathrm{KD}_{1}, \mathrm{KQ}_{1} \quad \mathrm{~d}$ and $\mathrm{q}$ componenets of outer screen

$\mathrm{KD}_{2}, \mathrm{KQ}_{2} \quad \mathrm{~d}$ and $\mathrm{q}$ components of inner screen 

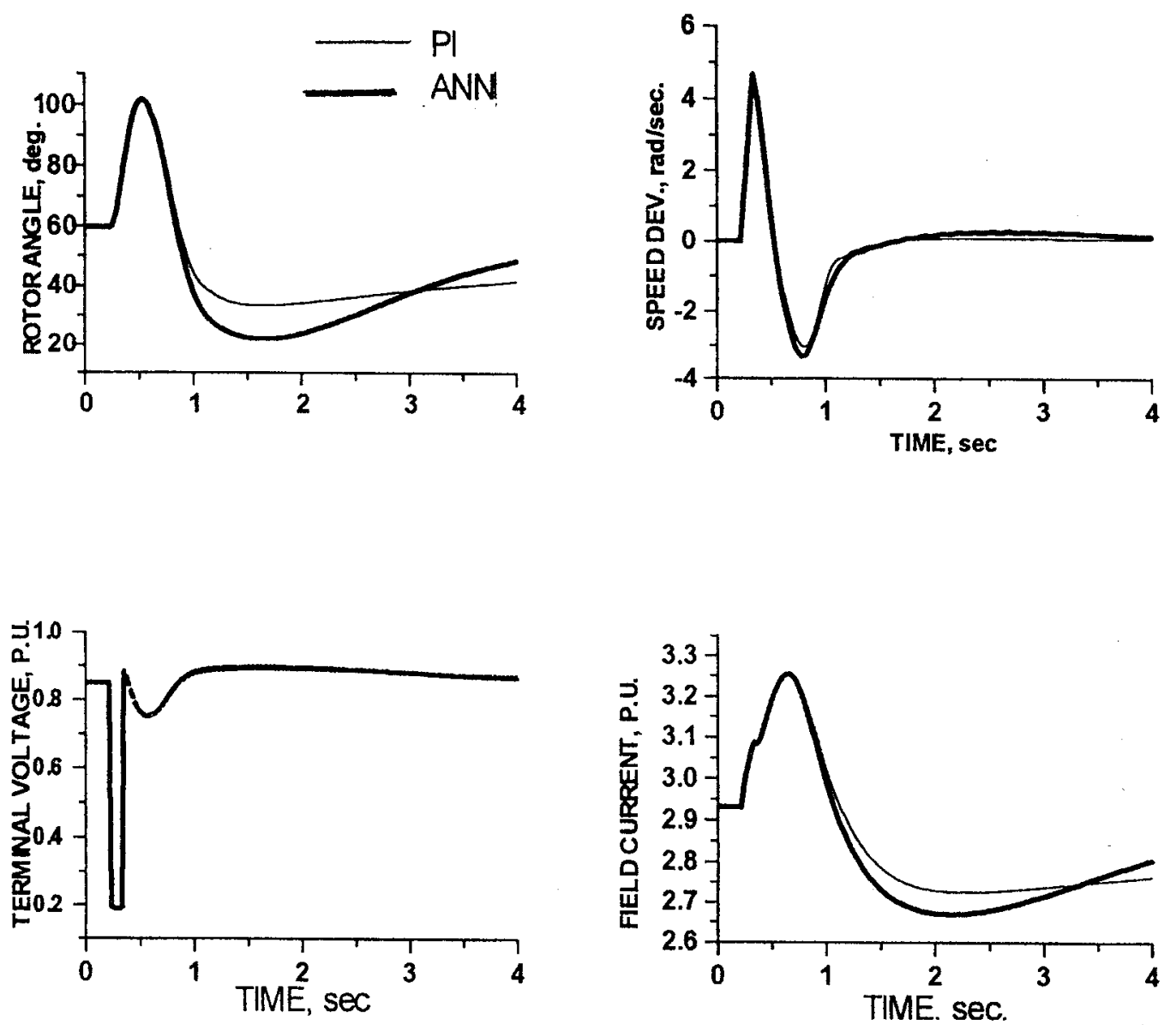

Fig.(3)System response to 3-phase s.c. (lead power factor) 

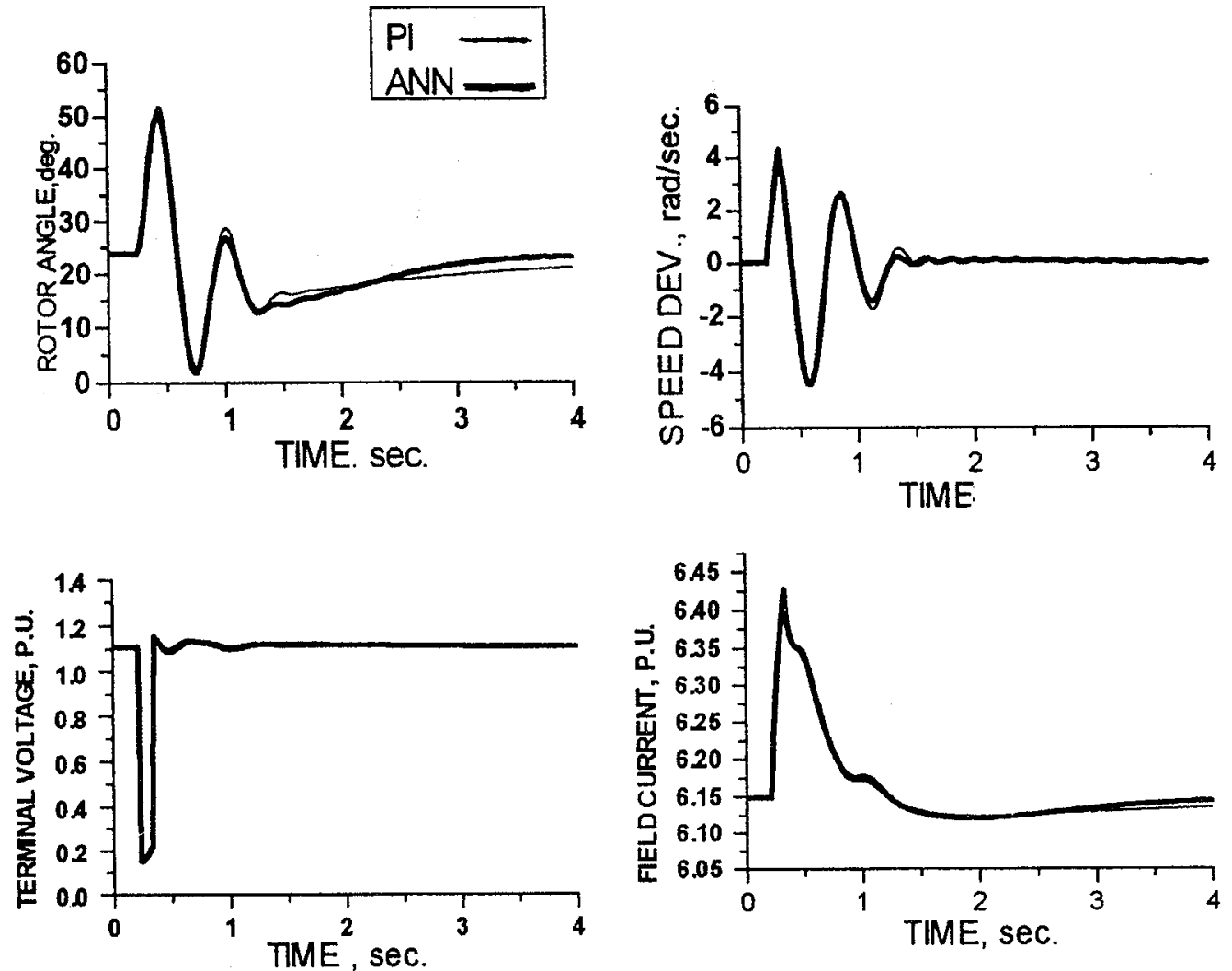

Fig.(4) System response to 3-phase s.c. (lag power factor) 

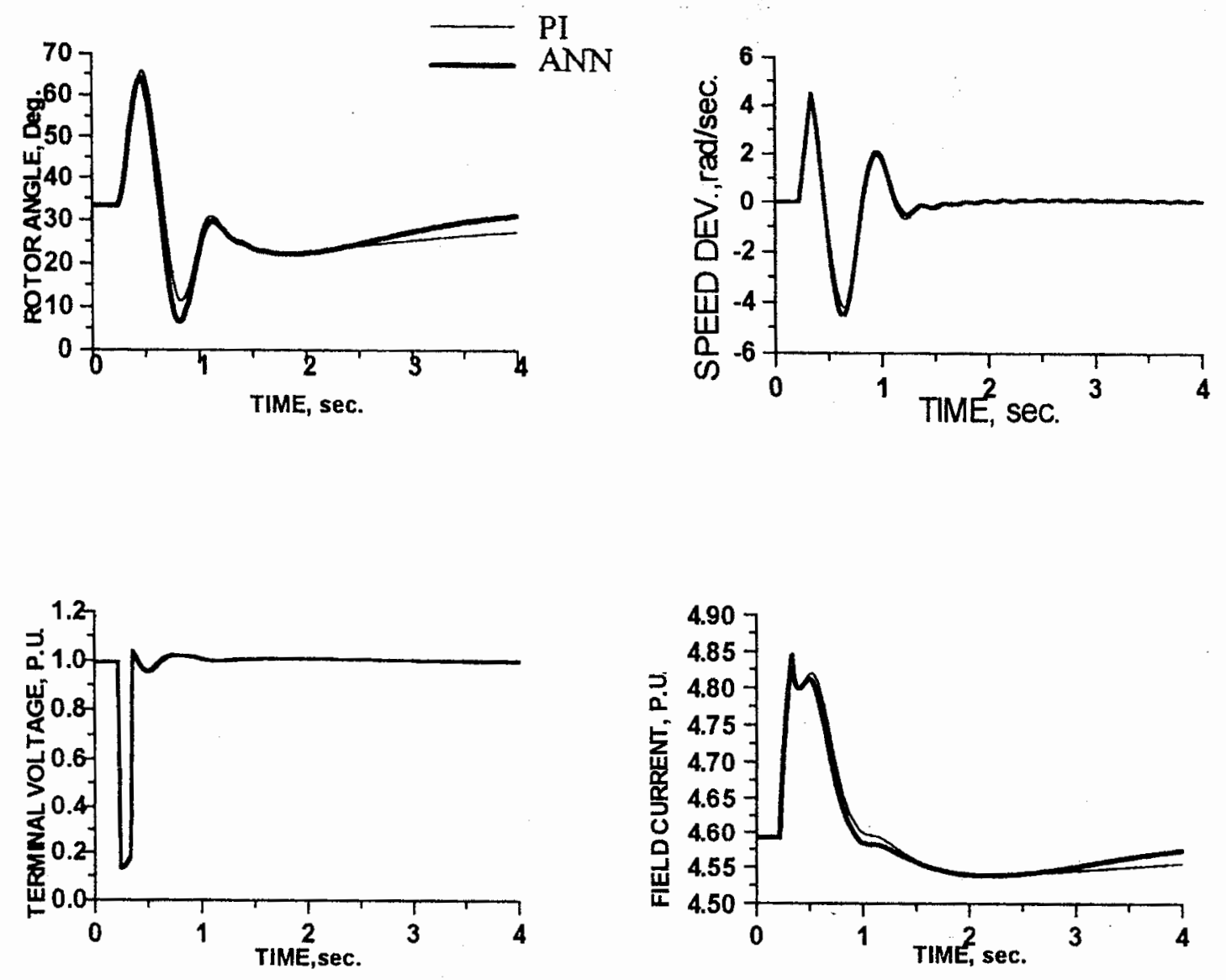

Fig.(5) System response to 3-phase s.c. (unity power factor) 


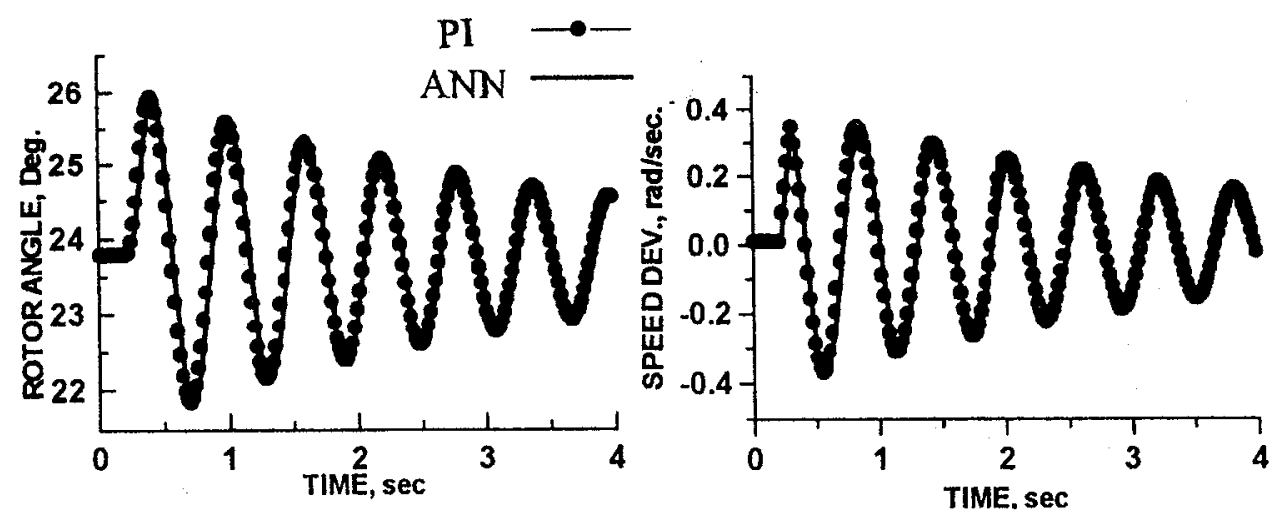

A

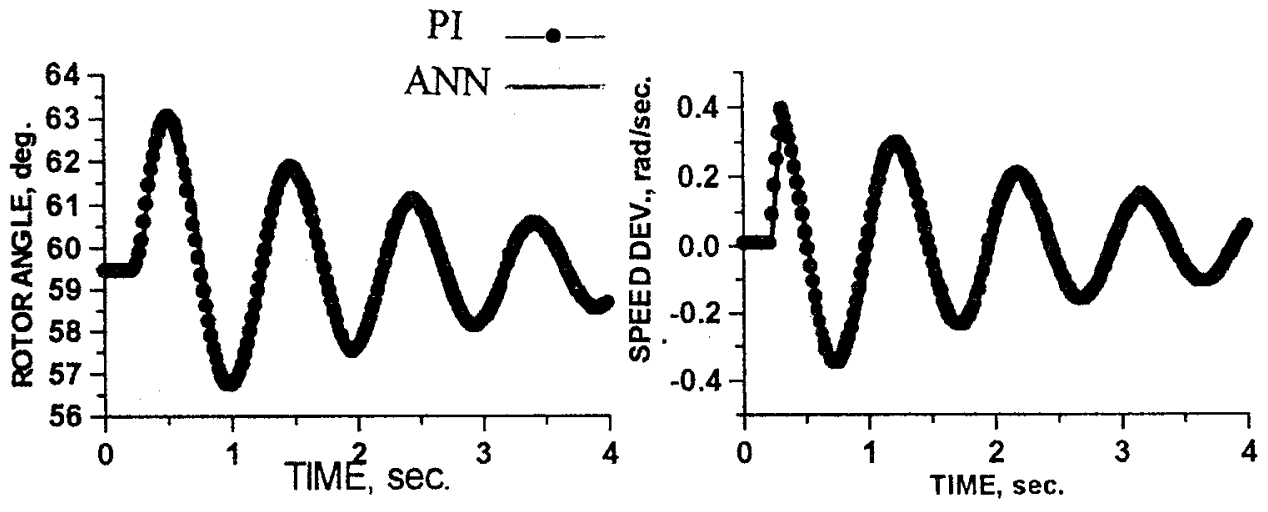

B

Fig.(6) System response To $10 \%$ increase in mechanical input A- lag power factor B- lead power factor 


\title{
تصميم دوائر عصبية اصطناعية كحاكم تناسبي تكامليي لآلة فاتقة التوصيل
}

\author{
داهر عبد الفثاح حممد \\ داجمال عبد الوهاب مرسي
}

لمواجهة الطلب المتزايد علي استهلاك الطاقة الكهربية استخدمت الآلات الفائقة التوصيل كأحد الحلول لنلك المشكلة ـ و الآلات فائقة التوصيل معقدة التركيب و تصميم حاكمات لها يحتاج عناية خاصة.

في السنوات الأخيرة جذبت الدوائر العصبية الاصطناعية الأنظار كنظم جديدة يتــــم تريبــها

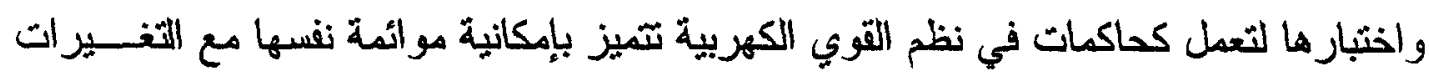
في ظرون التشغيل أو الأخطاء المختلفة.

هذا البحث يقتر ح دائرة عصبية اصطناعية تعمل كحاكم تتاسبي تكاملي في دائرة منظم البخـار

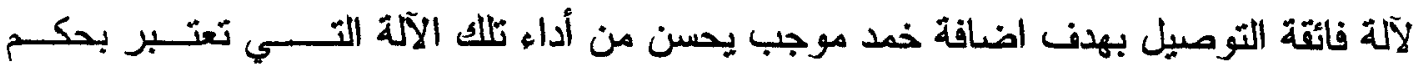

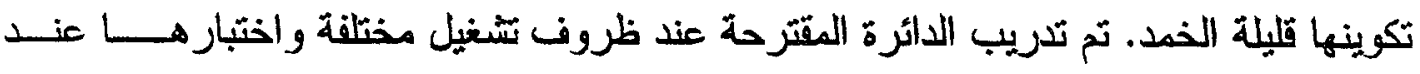

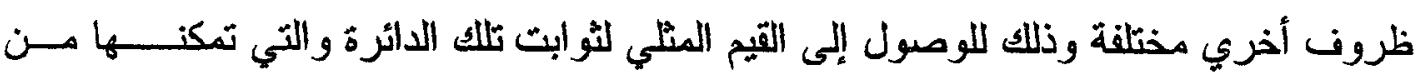
الأداء بشكل جيد.

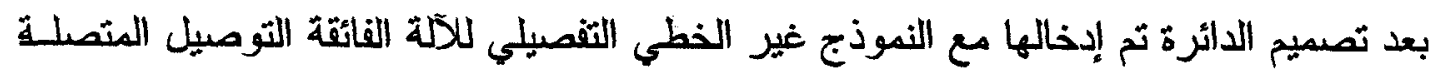

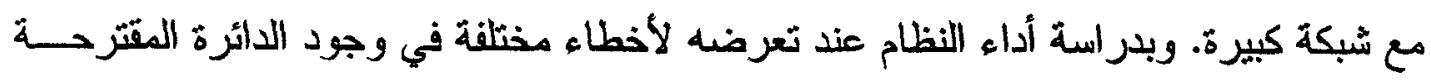

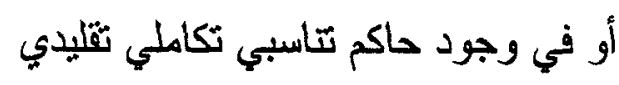

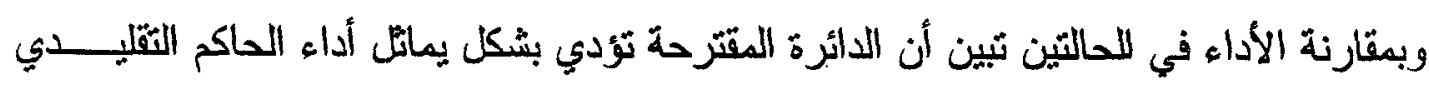



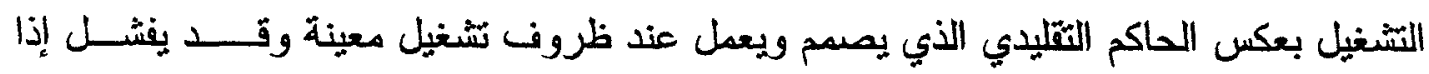
تغيرت ظروف التشغيل. 